\title{
The anatomy of melancholia: does frontal-subcortical pathophysiology underpin its psychomotor and cognitive manifestations?
}

The last few years have witnessed a major paradigm shift in the understanding of basal ganglia function. In line with this has been an increasing appreciation of both the centrality of psychomotor deficits in melancholia and the striking clinical parallels between melancholia and certain basal ganglia disorders such as Parkinson's disease. It is in view of these developments that a more considered appraisal of the role of the basal ganglia and their frontal connections in the pathogenesis of melancholia has become possible.

'Endogenous' or 'melancholic' depression has been regarded by many as a categorical entity with its own pathophysiological underpinnings (Carney et al. 1965), though classification of the depressive disorders remains contentious (Kendell, 1968). Among a number of statistical attempts to separate melancholic and non-melancholic depression, some factor analytical studies have demonstrated that psychomotor retardation may be one of the best discriminators of these two syndromes (Nelson \& Charney, 1981). Within this context the last decade has seen a re-evaluation of the clinical features of melancholia, with increased interest in the objective or behavioural aspects both motor and cognitive - of this disorder. In particular, motor disturbance is gaining increasing attention as a potential core behavioural manifestation of melancholia (Widlocher, 1983; Parker $e t$ al. 1990, 1994). Cognitive deficits are also a prominent feature, especially in elderly and/or severely depressed patients, where the impairment is sometimes of such magnitude that these patients have been described as suffering from a 'depressive pseudodementia' (Kiloh, 1961) or 'depressive dementia' (Stoudemire et al. 1989).

Concurrent with this focus upon behavioural aspects of depression has been the development of the concept of 'sub-cortical dementia'. This term was introduced by Albert et al. (1974) to describe the clinical presentation of disorders with predominant subcortical pathology such as progressive supranuclear palsy, Parkinson's disease, Huntington's Chorea and Wilson's disease which are characterized by slowed mentation and movement, apathy, depression and reduced ability to manipulate acquired knowledge. In view of the significant 'frontal' executive deficits also noted in these disorders, the term was subsequently revised by Albert (1978) to 'frontal-subcortical dementia'. Although the clinical validity of both 'sub-cortical dementia' and 'depressive dementia' has since been questioned (Mahendra, 1985), the use of these terms has led to another important conceptual shift: from defining functional psychiatric disorders, including depression, in purely phenomenological terms to viewing them in terms of regional cerebral dysfunction and disruption of neuronal networks.

Traditionally, the basal ganglia were considered to be involved only in the modulation of movement. More recently, however, Alexander et al. (1986) have proposed the existence of a number of functional neural networks passing through the basal ganglia that may impact not only on motor function but also cognitive processes and mood. For example, motor disturbance could result from dysfunction of Alexander et al.'s (1986) 'motor loop'. Mood and motivational disturbances seen in these disorders could be related to dysfunction in the 'limbic loop' linking medial prefrontal structures with the ventral striatum, and cognitive deficits to disturbances in the 'prefrontal loop' linking lateral prefrontal structures to the caudate nucleus.

\footnotetext{
' Address for correspondence: Dr Marie-Paule Austin, Psychiatry Unit, Prince Henry Hospital, Anzac Parade, Little Bay, Sydney, NSW 2036, Australia.
} 
The major evidence for Alexander et al.'s (1986) circuits comes from primate studies suggesting hitherto unrecognized functional diversity in the basal ganglia. Specifically, these investigations have examined the behavioural correlates of both single cell recordings from basal ganglia neurons (Goldman-Rakic, 1982; Alexander \& DeLong, 1985) and experimental lesions in the basal ganglia themselves. In addition, autoradiographic (Kunzle, 1975; Kalil, 1978) and histochemical studies (Graybiel \& Ragsdale, 1978) of the connections between basal ganglia and cortical regions have clearly demonstrated frontal-subcortical pathways.

There are a small number of clinical studies in patients with basal ganglia pathology, which are suggestive of dysfunction of these putative networks. Laplane et al. (1989) and Mendez et al. (1989) in their study of patients with basal ganglia lesions, and Weinberger et al. (1988) in Huntington's Chorea patients, have all reported significant correlations between the 'frontal' behavioural and cognitive deficits commonly found in these subjects, and basal ganglia atrophy as demonstrated by structural imaging. Playford et al. (1992), using PET to investigate the pattern of cerebral blood flow associated with the performance of 'willed' motor tasks in PD patients, have found impaired activation in a number of cerebral regions which have been implicated in Alexander et al.'s (1986) 'motor loop'.

This editorial reviews the evidence from recent neurobiological studies of depression that may implicate a role for the basal ganglia and its frontal connections in the pathogenesis of melancholia. Using Parkinson's disease - the most common, and best studied of the 'frontal-subcortical' dementias - as a putative model for the psychomotor aspects of melancholia, we develop a neuroanatomical and neurochemical formulation of the pathogenesis of melancholia incorporating the concepts of Alexander et al. (1986).

\section{AFFECTIVE, MOTOR AND COGNITIVE DYSFUNCTION IN PARKINSON'S DISEASE AND MELANCHOLIA: SOME PARALLELS}

Depression occurs with an increased frequency in patients with disorders involving basal ganglia pathology. This is particularly the case with Parkinson's disease (PD), where rates of depression of between 4 and $90 \%$ (mean $40 \%$ ) have been reported (Cummings, 1992).

Because of the long-standing historical dichotomy between psychiatric and neurological disorders, comparisons between the motor manifestations of melancholia and particular aspects of PD have rarely been highlighted. There is, however, a striking resemblance between the bradykinesia of PD and the motor slowing seen in retarded melancholia. PD patients who are not depressed also often exhibit a slowness of thought or 'bradyphrenia', that is indistinguishable from that seen in melancholic patients (Rogers, 1986) and which is a key feature of the 'frontalsubcortical' dementias. This slowing of thought has been investigated in both PD (Evarts et al. 1981; Rafal et al. 1984) and melancholia (Byrne, 1977; Cornell et al. 1984; Hart \& Kwentus, 1987; Parker et al. 1994) by means of reaction time (RT) studies assessing both cognitive and motor speed. Most of these studies report equivalent prolongation of both components of the RT in the two disorders.

It is now commonly accepted that depression is associated with a number of cognitive deficits, especially in the areas of memory, attention and speed of processing (Cronholm \& Ottoson, 1961; Sternberg \& Jarvik, 1976; Stromgren, 1977; Weingartner et al. 1981; Cohen et al. 1982; Roy-Byrne et al. 1986; Wolfe et al. 1987; Austin et al. 1992a; Brand et al. 1992). Impairment on so-called 'frontal' tasks has also been consistently demonstrated in depression, particularly in the more severely depressed subjects (Raskin et al. 1982; Silberman et al. 1983; Pendleton Jones et al. 1987; Cassens et al. 1990; Austin et al. 1992a; Channon et al. 1993).

Impairment is found in a range of cognitive functions in PD patients (Boyd et al. 1991) even after accounting for the effects of medication, functional disability and depressed mood (Levin et al. 1992). Of greater significance is the fact that this cognitive impairment is seen even in early, untreated PD (Cooper et al. 1991). As in depressed patients, poor performance is seen on 'effortful' 
rather than 'automatic' verbal memory tasks (Weingartner et al. 1984), tasks of executive function, shifting of cognitive set (Phillips \& Carr, 1987) and visuospatial tasks (Levin et al. 1992). It is noteworthy that these patients are particularly impaired in the performance of tasks reliant on internal cues and strategies while performance is normal where external cues are provided (Brown \& Marsden, 1988). Taylor et al. (1986) have hypothesized that dopamine pathways may be in part responsible for this impairment of these so-called 'willed' acts in PD, while Alexander et al. (1990) implicate the "motor' circuit in performance of self-generated motor acts.

While there is little correlation between motor disability and cognitive impairment in PD (Cooper et al. 1991), cognitive deficits tend to be associated with concurrent depression. For example, Starkstein et al. (1989), in a matched control study examining cognitive impairment in PD patients with and without depression, found that the depressed PD patients performed significantly worse than the non-depressed PD subjects on all aspects of neuropsychological function, but especially frontal tasks. The pattern of deficits seen in the depressed PD group was strikingly similar to that reported in Austin et al.'s (1992a) 'endogenously' depressed patients. Starkstein et al. (1989) went on to hypothesize that both cognitive impairment and depressive disorder in PD might be associated with pathological changes in dopaminergic neurons located in the ventral tegmental area, an integral component of the mesolimbic network. This suggestion is consistent with the post-mortem findings of Torack \& Morris (1988), who noted marked loss of these neurons in patients who had previously been clinically assessed as presenting with parkinsonism, cognitive deficit and depression.

\section{IDENTIFYING ABNORMAL REGIONS AND NETWORKS IN DEPRESSION}

What evidence is there from studies of abnormal structure or function (metabolic or biochemical) in depressed patients, to indicate that anatomical regions thought to be involved in Alexander et al.'s (1986) putative functional networks may be implicated in the pathophysiological mechanisms underpinning the psychomotor deficits of melancholia?

\section{Imaging studies}

(i) Functional imaging

The introduction of imaging techniques such as PET (Positron Emission Tomography) and SPECT (Single Photon Emission Computerized Tomography) to quantify changes in regional cerebral blood flow (rCBF) and metabolism holds the potential to elucidate the neuroanatomical substrates of melancholia. In depression, Sackeim et al. (1990) and Delvenne et al. (1990) in their large and well designed ${ }^{133} \mathrm{Xe}$ blood flow studies, found reduced global cortical flow in their subjects at rest. These studies were limited by their inability to quantitate sub-cortical flows. A number of ${ }^{18} \mathrm{FDG}$ PET studies examining small samples of depressives, have found relative hypometabolism in the frontal lobes (Baxter et al. 1989; Hurwitz et al. 1990; Martinot et al. 1990) and caudate nuclei (Baxter et al. 1985; Buchsbaum et al. 1986; Hagman et al. 1990) of depressed subjects, thus supporting the possibility of prefrontal cortex and caudate dysfunction in these patients.

Studies specifically investigating patients with more severe forms of depression-endogenous, melancholic and psychotic-have been infrequent and at times conflicting in their findings. However, there is a general consensus that rCBF abnormalities in these patients occur predominantly in sub-cortical and frontal areas. For example, in a ${ }^{99 \mathrm{~m}}$ Tc-HMPAO SPECT study comparing subjects with endogenous and non-endogenous depression, Austin et al. (1992b) found a positive correlation between Newcastle scores and frontal and cingulate $\mathrm{CBF}$ in the psychotic and most severely depressed group. An ${ }^{15} \mathrm{O}_{2}$ PET study of 'severely depressed', elderly patients (Bench et al. 1992), showed reduced rCBF in the left dorsolateral prefrontal cortex (DLPFC) and anterior cingulate in the group as a whole and further left orbitofronto-medial reduction in the more cognitively impaired subjects. Similarly, Delvenne et al. (1990) reported greater left hemisphere reduction in their endogenous group.

It is not clear whether these regional abnormalities in predominantly limbic structures are trait or state dependent. Martinot et al. (1990), found disappearance of left-right asymmetry but 
persisting hypofrontality upon recovery. Baxter et al. (1989) on the other hand, showed normalization of relative left DLPFC hypometabolism after treatment with antidepressants. Bench et al. (1993) rescanning 25 of their original 33 depressed patients, found that remission was associated with significant normalization in left dorsolateral prefrontal cortex rCBF but not in the cingulate and angular gyri. In contrast, Goodwin et al. (1993) using ${ }^{99 \mathrm{~m}}$ Tc-HMPAO with SPECT, found persistent hypofrontality in recovered patients in conjunction with a return to normal perfusion in limbic and subcortical structures. These authors concluded that the state-dependent changes in $\mathrm{rCBF}$ might be indicative of reversible disruption of mesolimbic dopaminergic pathways in depressed subjects.

\section{(ii) Structural imaging}

Magnetic resonance imaging (MRI), with its ability to provide sharp resolution of both cortical and subcortical structures, provides a useful adjunct to the investigation of the anatomical correlates of melancholia. Recent studies have highlighted the existence of a sub-group of older melancholic subjects with associated deep white matter (DWM), striatal and periventricular hyperintensities (Coffey et al. 1990; 1993). Furthermore, Brown et al. (1992) in a controlled study of patients with a variety of psychiatric disorders, found significantly more frequent and severe hyperintensities only in depressed subjects over the age of 45 . Although the pathophysiological significance of these lesions is not clear, it is possible that they may reflect microvascular lesions disrupting functional networks such as those described by Alexander et al. (1986). Significant volumetric reduction reported in both the frontal cortex (Coffey et al. 1993) and subcortical nuclei (Krishnan et al. 1992) of depressed patients is further evidence suggestive of structural disruption in putative frontalsubcortical networks.

To date there has been a dearth of studies correlating structural and functional abnormalities in depressed patients (Sackeim \& Prohovnik, 1993). Thus, the interaction between volumetric reduction and DWM lesions, and changes in the pattern of $\mathrm{CCBF}$ remains to be elucidated.

\section{Biochemical studies: dopaminergic dysfunction in depression}

The striking clinical parallels between melancholia and $\mathrm{PD}-\mathrm{a}$ disorder with predominant disturbance of dopaminergic transmission-suggest the possibility of a similar biochemical disturbance in melancholia. Biochemical disturbance in depression has been ascribed to a number of different neurotransmitter systems, with traditional accounts focusing largely upon noradrenaline and serotonin. In contrast, the potential role of dopamine has, until recently, been largely overlooked with some few exceptions (Willner et al. 1991; Kapur \& Mann, 1992). While not subscribing to any 'single amine' hypothesis of affective disorders, this review will emphasize upon the role of dopamine, particularly in light of our focus upon basal ganglia function in depression.

There are several lines of evidence pointing to reduced dopaminergic function in melancholia: $(i)$ the biochemistry of animal models of depression; (ii) the study of dopamine metabolites in depressed subjects; and (iii) the effect of dopamine agonists and certain antidepressants on affect and cognition.

\section{(i) Animal models of depression}

Although animal models of depression have been controversial and often difficult to interpret, biochemical studies of these models have lent considerable support for an important role of dopamine in this condition. In the 'learned helplessness' model, animals exposed to inescapable stressors exhibit decreased spontaneous activity which is not only reversed by antidepressants (Sherman et al. 1982), but is also both prevented by prior treatment with dopamine agonists and associated with dopamine depletion in the substantia nigra (Anisman et al. 1979). It has also been hypothesized that certain reward-related neural systems are impaired in depression, as anhedonia is a cardinal feature of this condition. Animal studies suggest that mesolimbic dopamine projections play a major role in the processing of reward related information and the selection and elaboration of motivated behaviour (Phillips \& Fibiger, 1978). Thus, Willner et al. (1991) conclude that "these properties make a dysfunction of the mesolimbic system a prime candidate to mediate such core 
features of melancholia as anhedonia and loss of motivation'. Interestingly, however, these authors make no mention of the potential neurochemical dysfunction underlying the motor deficits seen in melancholia.

(ii) Biochemical studies

A number of studies have attempted to assess forebrain dopaminergic function in depressed patients by measuring concentrations of homovanillic acid (HVA) in the CSF. Van Praag et al. (1975) examined dopamine metabolism in endogenous patients with severe psychomotor retardation and found that like PD subjects, HVA concentrations in melancholic subjects were about half those of both matched controls and non-melancholic subjects. After treatment with L-dopa, motor retardation in the low HVA group largely disappeared and HVA levels normalized despite a lack of improvement in the mood state. While some workers (Elsworth et al. 1987) claim that CSF HVA is mainly derived from frontal structures, others attribute its origin to the dorsal striatum with only a minor contribution from mesolimbic structures (Sourkes, 1973). These conflicting results, rather than detracting from our thesis, serve to strengthen the postulate that melancholia is a disorder of both psychomotor function and mood which is associated with abnormalities in both the nigrostriatal and mesolimbic dopaminergic systems.

(iii) Effect of dopamine agonists on mood and cognitive function Manipulation of dopaminergic transmission using dopamine agonists in depressed patients has produced some intriguing results. Van Kammen \& Murphy (1975) reported a marked enhancement in mood and activation in a group of depressed patients after a single dose of amphetamine. L-dopa has been shown to be effective in treating some patients with retarded depression, leading to an initial reduction in motor symptoms with a subsequent improvement in mood (Goodwin \& Sack, 1974). Other dopamine agonists such as bromocriptine (Colonna et al. 1979) and piribedil (Post et al. 1978) have also been reported to be effective in the treatment of depressed patients.

Antidepressants with specific dopaminergic agonistic action such as nomifensine and amineptine (a selective dopamine reuptake inhibitor) have been shown to be particularly effective in the treatment of melancholia with motor retardation (van Scheyen et al. 1977; Rampello et al. 1991).

In depressed patients, the use of dopamine agonists has been shown to improve performance on 'effortful' memory tasks (Murphy et al. 1972; Henry et al. 1973; Reus et al. 1979) independent of the mood state. Holcomb (1985), in a review of the role of dopaminergic pathways in depression and parkinsonism, commented that 'dopamine agonists clearly improve effortful cognitive functions. In contrast Parkinson's disease and depression impair memory tasks requiring sustained mental effort. In both illnesses it appears that this cognitive behavioural disturbance is partially dependent on dopamine pathway pathology'.

\section{DISCUSSION AND FUTURE DIRECTIONS}

This editorial of the behavioural, cognitive and motor abnormalities of both melancholia and PD highlights the many similarities between the two disorders. Furthermore, the majority of the studies outlined suggest that dysfunction at the level of the prefrontal cortex and the basal ganglia contributes significantly to the pathogenesis of melancholic depression. On the basis of the evidence reviewed in this editorial, it would seem reasonable to postulate that dysfunction in a number of the functional circuits proposed by Alexander et al. (1986) may explain at least some of the clinical features of both PD and melancholia.

While we are proposing a putative anatomical localization for melancholic depression, we would emphasize that this may involve either a functional or structural disruption of the relevant regions or pathways. Recurrent episodes with subsequent recovery may be understood as reflecting intermittent periods of abnormal function - perhaps precipitated by life events - in genetically vulnerable individuals. On the other hand, the treatment resistance or lack of full recovery often seen in patients with predominantly late onset melancholia may be explained by structural, and thus potentially irreversible, disruption in these functional networks. The recent MRI studies of 
elderly melancholic subjects identifying deep white matter and sub-cortical grey 'hyperintensities' (thought to represent areas of microvascular ischaemia) would support the possibility of such structural lesions. Where the lesions of themselves are of insufficient severity to lead to symptoms, this might occur with the addition of a stressor such as a negative life event (Krishnan, 1993).

A modulatory and integratory role for dopamine in Alexander et al.'s (1986) functional networks has now been postulated by Krishnan (1993), who states that 'dopamine neurons may provide the interface between motor and limbic loops (at the level of the basal ganglia)'. Furthermore, Strange (1993) has proposed that 'the functional linkage of the ventral striatum to the (dorsal) neostriatum, may provide a means for emotion and motivational influences to alter basic control of movement'.

The biochemical studies of retarded melancholia suggest a reduction of dopamine activity in striatal pathways, which in turn are likely to impact upon Alexander et al.'s (1986) 'motor loop'. The added presence of motor agitation in some retarded melancholic patients is more difficult to incorporate into this hypothesis, but may be explained either as a paradoxical increase in dopamine function in these same pathways, or alternatively as a manifestation of more extensive dysfunction to the 'motor loop'. Psychotic symptoms, which are also often present in agitated melancholic subjects, may be related to increased mesolimbic dopamine activity - analogous to the formulation of Davis et al. (1991) who suggested this mechanism to explain the co-existence of positive and negative symptoms in schizophrenia. By acknowledging the potentially variable and often interdependent involvements of a number of these functional neural networks in the production of melancholia, we can attempt to encompass the variations in psychomotor disturbance and psychotic symptoms seen in individual subjects.

This central hypothesis proposed by ourselves and others (Krishnan, 1993) - that dopamine-rich regions of the prefrontal cortex and the basal ganglia, acting as components of a number of functionally related neural networks, are primary sites of dysfunction in melancholia - is amenable to testing using a number of different approaches. This hypothesis might best be tested using a combination of neuroimaging, biochemical and neurocognitive investigations. Such a 'convergence of evidence' approach as advocated by Carpenter et al. (1993), should clarify this postulated role of the basal ganglia and frontal regions in the enigma that is melancholia.

MARIE-PAULE AUSTIN AND PHILIP MITCHELL

Thanks are due to Associate Professor P. Sachdev for valuable comments on the first draft of the paper.

\section{REFERENCES}

Albert, M. L. (1978). Subcortical dementia. In Alzheimer's Disease: Senile Dementia and Related Disorders (ed R. Katzman, R. D. Terry and K. L. Birch), pp. 173-180. Raven Press: New York.

Albert, M. L., Feldman, R. G. \& Willis, A. L. (1974). The 'subcortical dementia of progressive supranuclear palsy. Journal of Neurology, Neurosurgery \& Psychiary 37, 121-130.

Alexander. G. E. \& De Long. M. R. (1985). Microstimulation of the primate neostriatum. II. Somatotopic organization of striatal microexcitable zones and their relation to neuronal response properties. Journal of Neurophysiology 53, 1417-1430

Alexander, G. E., De Long, M. R. \& Strick, P. L. (1986). Parallel organisation of functionally segregated circuits linking basal ganglia and cortex. Ammual Review of Neuroscience 9, 357-381.

Alexander. G. E.. Crutcher. M. D. \& DeLong, M. R. (1990). Basal ganglia-thalamocortical circuits: parallel substrates for motor, oculomotor. 'prefrontal' and 'limbic' functions. Progress in Brain Research 85. 119-146.

Anisman. H.. Irwin. J. \& Sklar. L. S. (1979). Deficits of escape performance following catecholamine depletion: implications for behavioural deficits induced by uncontrollable stress. Psychopharmacology 64, 163-170.

Austin. M.-P., Ross. M., Murray, C.. O'Carroll, R. E.. Ebmeier, K. P. \& Goodwin. G. M. (1992a). Cognitive function in major depression. Journal of Affective Disorders 25. 21-30.

Austin. M.-P.. Dougall. N.. Ross. M.. Murray, C.. O'Carroll, R. E.. Moffoot. A.. Ebmcicr. K. P. \& Goodwin. G. M. (1992b). Single photon emission tomography with ${ }^{89 m}$ Tc-exametazime in major depression and the pattern of brain activity underlying the psychotic/neurotic continuum. Journal of Affective Disorders 26 , $31-44$.

Baxter, L. R., Phelps, M. E., Mazziotta, J. C., Schwartz, J. M., Gerner, R. H., Selin, C. E. \& Sumida, R. M. (1985). Cerebra] metabolic rates for glucose in mood disorders. Archives of General Psychialry' 42, 441-447.

Baxter, L. R., Phelps, M. E., Mazziotta, J. C., Guze, B. H., Selin, C. E., Gerner, R. H. \& Selin, C. E. (1989). Reduction of prefrontal cortex glucose metabolism common to three types of depression. Archives of General Psychiatry 46, 243-250.

Bench, C. J., Friston, K. M., Brown, R. G., Scott, L. C., Frackowiak, S. J. \& Dolan, R. J. (1992). The anatomy of melancholia - focal abnormalities of cerebral blood flow in major depression. Psychological Medicine 22, 606-615.

Bench, C. J., Dolan, R. J., Friston, K. J. \& Frackowiak, R. S. J. (1993). State and trait abnormalities of regional cerebral blood flow in depression determined by positron emission tomography. Journal of Cerebral Blood Flow and Metabolism 13, 503.

Boyd, J. L.. Cruickshank, C. A., Kenn, C. W., Madeley, P., Mindham. R. H. S., Oswald, A. G., Smith, R. J. \& Spokes, E.G.S. (1991). Cognitive impairment and dementia in Parkinson's disease: a controlled study. Psychological Medicine 21, 911-321.

Brand. A. N., Jolles, J. \& Gispen-de Wied, C. (1992). Recall and recognition memory deficits in depression. Jourmal of Affective Disorders 25, 77-86. 
Brown, R.G. \& Marsden, C. D. (1988). 'Subcortical Dementia': the neuropsychological evidence. Neuroscience 25, 363-387.

Brown, F. W., Lewine, R. J., Hudgins, P. A. \& Risch, S. C. (1992). White matter hyperintensity signals in psychiatric and nonpsychiatric subjects. American Journal of Psychiatry 149, 620-625.

Buchsbaum. M. S., Wu, J., De Lisi, L. E., Holcomb, H., Kessler, R., Johnson, J., King, A. C., Hazlett, E., Langston, K. \& Post, R. M. (1986). Frontal cortex and basal ganglia metabolic rates assessed by Positron Emission Tomography with $\left[{ }^{18} \mathrm{~F}\right] 2$-deoxyglucose in affective illness. Journal of Affective Disorders 10, 137-152.

Byrnc, D. G. (1977). Choice reaction times in depressive states. British Journal of Social and Clinical Psychology 15, 149-156.

Carney, M. W. P., Roth, M. \& Garside, R. F. (1965). The diagnosis of depressive syndrome and the prediction of ECT response. British Journal of Psychiarry 111, 659-674.

Carpenter, W. T. Jr, Buchanan, R. W., Kirkpatrick, B., Tamminga, C. \& Wood, F. (1993). Strong inference, theory testing, and the neuroanatomy of schizophrenia. Archives of General Psychiatry 50. $825-831$.

Cassens, G., Wolfe, L. \& Zola, M. (1990). The neuropsychology of depressions. Neuropsychology Update Series 2, 202-212.

Channon, S., Baker, J. E. \& Robertson, M. M. (1993). Working memory in clinical depression: an experimental study. Psychological Medicine 23, 87-91.

Coffey, C. E., Gigiel, G. S., Djang, W. T. \& Weiner, R. D. (1990). Subcortical hyperintensity on magnetic resonance imaging: a comparison of normal and depressed elderly subjects. American Journal of Psychiatry 147, 187-189.

Coffey, C. E., Wilkinson, W. E., Weinger, R. D., Parashos, I. A., Djand, W. T., Webb, M. C., Gigiel, G. S. \& Spritzer, C. E. (1993). Quantitative cerebral anatomy in depression: a controlled magnetic resonance imaging study. Archives of General Psychiatry 50, 7-16.

Cohen, R. M., Weingartner, H., Smallberg, S. A., Pickar, D. \& Murphy, D. L. (1982). Effort and cognition in depression. Archives of General Psychiatry 39, 593-598.

Colonna, L., Petit, M. \& Lepine, J. P. (1979). Bromocriptine in affective disorders: a pilot study. Journal of Affective Disorders 1, 173-177.

Cooper, J. A., Sagar, H. J., Jordan, N., Harvey, N. S. \& Sullivan, E. V. (1991). Cognitive impairment in early, untreated Parkinson's Disease and its relationship to motor disability. Brain 114, 2095-2122.

Cornell. D. G.. Suarez. R. \& Berent. S. (1984). Psychomotor retardation in melancholic and non-melancholic depression: cognitive and motor components. Journal of Abnormal Psychology 932, 150-157.

Cronholm, B. \& Ottosson, J. (1961). Memory function in endogenous depression. Archives of General Psychiatry 5, 193-197.

Cummings, J. L. (1992). Depression and Parkinson's disease: a review. American Journal of Psychiatry 149, 443-454.

Davis, K. L., Kahn, R. S., Ko, G. \& Davidson, M. (1991). Dopamine in schizophrenia: a review and reconceptualization. American Journal of Psychiarry 148, 1474-1486.

Delvenne, V., Delecluse, F., Hubain, P., Schoutens, A., De Maertclaer, V. \& Mendlewicz, J. (1990). Regional cerebral blood flow in patients with affective disorders. British Journal of Psychiarry 157, 359-365.

Elsworth, J. D., Leahy, D. J., Roth, R. H. \& Redmond, D. E., Jr (1987). Homovanillic acid concentrations in brain, CSF and plasma as indicators of central dopamine function in primates. Journal of Neural Transmission 68, 51-62.

Evarts, E. V., Teravainen, H. \& Calne, D. B. (1981). Reaction time in Parkinson's disease. Brain 104, 167-186.

Goldman-Rakic, P. S. (1982). Cytoarchitectonic heterogeneity of the primate neostriatum: subdivision into island and matrix cellular compartments. Journal of Comprehensive Neurology 205, 398-413.

Goodwin, F. K. \& Sack, R. L. (1974). Central dopamine function in affective illness: evidence from precursors, enzyme inhibitors and studies of central dopamine turnover. In Neuropsychopharmacology of Monoamines and their Regulatory Enzymes (ed. E. Usdin), pp. 73-101, Raven Press: New York.
Goodwin, G. M., Austin, M.-P., Dougall, N., Ross, M., Murray, C. O'Carroll, R. E., Moffoot, A., Prentice, N. \& Ebmeier, K.P. (1993). State changes in brain activity shown by the uptake of ${ }^{89 m}$ Tc-exametazime with single photon emission tomography in major depression before and after treatment. Journal of Affective Disorders 29, 243-253.

Graybiel, A. M. \& Ragsdale, C. W. (1978). Histochemically distinct compartments in the striatum of human being, monkey and cat demonstrated by the acetylthiocholinesterase staining method. Proceedings National Academy of Science USA 75, 5723-5726.

Hagman, J. O., Buchsbaum, M. S., Wu, J. C., Rao, S. J., Reynolds, C. A. \& Blinder, B. J. (1990). Comparison of regional brain metabolism in bulimia nervosa and affective disorder assessed with positron emission tomography. Journal of Affective Disorders 19. 153-162.

Hart, R. P. \& Kwentus, J. A. (1987). Psychomotor slowing and subcortical-type dysfunction in depression. Journal of Neurology, Neurosurgery and Psychiatry 50, 1263-1266.

Henry, G. M., Weingartner, H. \& Murphy, D. L. (1973). Influence of affective states and psychoactive drugs on verbal learning and memory. American Journal of Psychiatry 130, 966-971.

Holcomb, H. H. (1985). Parkinsonism and depression: dopaminergic mediation of neuropathologic processes in human beings. In The Catecholamines in Psychiatric and Neurologic Disorders (ed. C. Lake and M. G. Ziegler), pp. 269-282. Butterworths: Boston.

Hurwitz, T. A., Clark, C., Murphy, E., Klonoff, H., Martin, W. R. W. \& Pate, B. D. (1990). Regional cerebral glucose metabolism in major depressive disorder. Canadian Journal of Psychiatry 35, 684-688.

Kalil, K. (1978). Patch-like termination of thalamic fibers in the putamen of the rhesus monkey: an autoradiographic study. Brain Research 140, 333-339.

Kapur, S. \& Mann, J. (1992). Role of the dopaminergic system in depression. Biological Psychiary 32, 1-17.

Kendell, R. E. (1968). The Classification of Depressive Illness. Oxford University Press: London.

Kiloh, L. G. (1961). Pseudo-dementia. Acta Psychiarica Scandinavica. 37, 336-351.

Krishnan, K. R. (1993). Neuroanatomic substrates of depression in the elderly. Journal of Geriatric Psychiatry and Neurology 6, 39-58.

Krishnan, K. R., McDonald, K., Escalona, W. M., Doraiswamy, P. M., Na, C., Husain, M. M., Figiel, G. S., Boyko, O. B. Ellinwood, E. H. \& Nemeroff, C. B. (1992). Magnetic resonance imaging of the caudate nuclei in depression. Archives of General Psychiatry 49, 553-557.

Kunzle, H. (1975). Bilateral projections from precentral motor cortex to the putamen and other parts of the basal ganglia. An autoradiographic study in Macaca fascicularis. Brain Research 88, 1995-209.

Laplane, D., Levasseur, M., Pillon, B., Dubois, B., Baulac, M. Mazoyer, B., Dinh, S. T., Sett, G., Danze, F. \& Baron, J. C. (1989). Obsessive-compulsive and other behavioural changes with bilateral basal ganglia lesions. Brain 112, 699-725.

Levin, B. E., Tomer, R. \& Rey, G. J. (1992). Cognitive impairments in Parkinson's disease. Neurologic Clinics 10, 471-485.

Mahendra, B. (1985). Depression and dementia. Psychological Medicine 15, 227-236.

Martinot, J., Hardy, P., Feline, A., Huret, J.-D., Mazoyer, B., AttarLevy, D., Pappata, S. \& Syrota, A. (1990). Left prefrontal glucose hypometabolism in the depressed state: a confirmation. American Journal of Psychiatry 147, 1313-1317.

Mendez, M., Adams, N. L. \& Skoog Lewandowski, K. (1989). Neurobehavioral changes associated with caudate lesions. Neurology 39, 349-354.

Murphy, D. L., Henry, G. M. \& Weingartner, H. (1972) Catecholamines and memory: enhanced verbal learning during L-DOPA administration. Psychopharmacologia 27, 319-326.

Nelson, J. C. \& Charney, D.S. (1981). The symptoms of major depressive illness. American Journal of Psychiatry 138, 1-13. 
Parker, G., Hadzi-Pavlovic, D., Boyce, P., Wilhelm, K., Brodaty, H., Mitchell, P., Hickie, I. \& Eyers, K. (1990). Classifying depression by mental state signs. British Journal of Psychiatry 157, 55-65.

Parker, G., Hadzi-Pavlovic, D., Wilhelm, K., Hickie, I., Brodaty, H., Boyce, P., Mitchell, P. \& Eyers, K. (1994). Defining melancholia: properties of a refined sign-based measure. British Journal of Psychiatry 164, 316-326.

Pendleton Jones, B., Henderson, M. \& Welch, C. A. (1987). Executive functions in unipolar depression before and after electroconvulsive therapy. International Journal of Neuroscience 38, 287-297.

Phillips, A. G. \& Carr, G. D. (1987). Cognition and the basal ganglia: a possible substrate for procedural knowledge. Canadian Journal of Neurological Science 14, 381-385.

Phillips, A. G. \& Fibiger, H. C. (1978). The role of dopamine in maintaining intracranial self-stimulation in the ventral tegmentum, nucleus accumbens, and prefrontal cortex. Canadian Journal of Psychology 32, 58-66.

Playford, E. D., Jenkins, I. H., Passingham, R. E., Nutt, J., Frackowiak, R. S. J. \& Brooks, D. J. (1992). Impaired mesial frontal and putamen activation in Parkinson's disease: a positron emission tomography study. Annals of Neurology 32, 151-161.

Post, R. M., Gerner, R. H., Carman, J. S., Billin, C., Jimerson, D. C., Goodwin, F. K. \& Bunney, W. E. (1978). Effects of a dopamine agonist piribedil in depressed patients. Archives of General Psychiatry 35, 609-615.

Rafal, R. D., Posner, M. I., Walker, J. A. \& Friedrich, F. J. (1984). Cognition and the basal ganglia. Separating mental and motor components of performance in Parkinson's disease. Brain 107, 1083-1094.

Rampello, L., Nicoletti, G. \& Raffaele, R. (1991). Dopaminergic hypothesis for retarded depression: a symptom profile for predicting therapeutic responses. Acta Psychiatrica Scandinavica 84, 552-554.

Raskin, A., Friedman, A. S. \& Di Mascio, A. (1982). Cognitive and performance deficits in depression. Psychopharmacology Bulletin 18, 196-206.

Reus, V. I., Silberman, E., Post, R. M. \& Weingartner, H. (1979). D-amphetamine: effects on memory in a depressed population. Biological Psychiatry 14, 345-356.

Rogers, D., Lees, A. J., Trimble, M. \& Stern, G. M. (1986). Concept of bradyphrenia: a neuropsychiatric approach. Advances in Neurology 45, 447-450.

Roy-Byrne, P. P., Weingartner, H., Bierer, L. M., Thompson, K. \& Post, R. M. (1986). Effortful and automatic cognitive processes in depression. Archives of General Psychiatry 43, 265-267.

Sackeim, H. A. \& Prohovnik, I. (1993). Brain imaging studies of depressive disorders. In Biology of Depressive Disorders (ed J. J. Mann and D. J. Kupfer), pp. 205-258. Plenum Press: New York. Sackeim, H. A., Prohovnik, I., Moeller, J. R., Brown, R. P., Apter, S., Prudic, J., Devand, D. P. \& Mukherjee, S. (1990). Regional cerebral blood flow in mood disorders. I. Comparison of major depressives and normal controls at rest. Archives of General Psychiatry 47, 60-70.

Sherman, A. D., Sacquitine, J. L. \& Petty, F. (1982). Specifity of the learned helplessness model of depression. Pharmacology, Biochemistry and Behaviour 16, 449-454.
Silberman, E. K., Weingartner, H. \& Post, R. M. (1983). Thinking disorder in depression. Archives of General Psychiatry 40, 775-780.

Sourkes, T. L. (1973). On the origin of homovanillic acid (HVA) in the cerebrospinal fluid. Journal of Neural Transmission 34, 153-157.

Starkstein, S. E., Preziosi, T. J., Berthier, M. L., Bolduc, P. L. Mayberg, H. S. \& Robinson, R. G. (1989). Depression and cognitive impairment in Parkinson's disease. Brain 112, 1141-1153.

Sternberg, D. E. \& Jarvik, M. E. (1976). Memory functions in depression. Archives of General Psychiatry 33, 219-224.

Stoudemire, A., Hill, C., Gulley, L. R. \& Morris, R. (1989). Neuropsychological and biomedical assessment of depressiondementia syndromes. Journal of Neuropsychiatry 1, 347-361.

Strange, P. G. (1993). Dopamine receptors in the basal ganglia: relevance to Parkinson's disease. Movement Disorders 8, 263-270.

Stromgren, L. S. (1977). The influence of depression on memory. Acta Psychiatrica Scandinanica 56, 109-128.

Taylor, A. E., Saint-Cyr, J. A. \& Lang, A. E. (1986). Frontal lobe dysfunction in Parkinson's disease. Brain 109, 845-883.

Torack, R. M. \& Morris, J. C. (1988). The association of ventral tegmental area histopathology with adult dementia. Archives of Neurology 45, 497-501.

van Kammen, D. P. \& Murphy, D. L. (1975). Attenuation of the euphoriant and activating effects of $\mathrm{D}$ - and $\mathrm{L}$-amphetumine by lithium carbonate treatment. Psychopharmacologia (Berlin), 44, 215-224.

van Praag, H. M., Korf, J., Lakke, J. P. W. F. \& Schut, T. (1975) Dopamine metabolising in depression, psychoses and Parkinson's disease: the problem of specificity of biological variables in behaviour disorders. Psychological Medicine 5, 138-146.

van Scheyen, J. D., Van Praag, H. M. \& Korf, J. (1977). Controlled study comparing nomifensine and clomipramine in unipolar depression, using the probenicid technique. British Journal of Psychiatry 4, 179S-184S.

Weingartner, H., Cohen, R. M., Murphy, D. L., Martello, J. \& Gerdt, C. (1981). Cognitive processes in depression. Archives of General Psychiatry 38, 42-47.

Weingartner, H., Burns, S., Diebel, R. \& Le Witt, P. A. (1984). Cognitive impairments in Parkinson's disease: distinguishing between effort-demanding and automatic cognitive processes. Psychiatry Research 11, 223-235.

Weinberger, D. R., Berman, K. F., Iadarola, M., Driesen, N. \& Zec, R. F. (1988). Prefrontal cortical blood flow and cognitive function in Huntington's Disease. Journal of Neurology, Neurosurgery, and Psychiatry 51, 94-104.

Widlöcher, D. J. (1983). Psychomotor retardation: clinical, theoretical and psychometric aspects. Psychiarric Clinics North America 6, 27-40.

Willner, P., Muscat, R., Papp, M. \& Sampson, D. (1991). Dopamine, depression and anti-depressant drugs. In The Mesolimbic Dopamine System: From Motivation to Action (ed. P. Willner and J. ScheelKruger), pp. 387-410. John Wiley \& Sons: New York.

Wolfe, J., Granholm, E., Butters, N., Saunders, E. \& Janowski, D. (1987). Verbal memory deficits associated with major affective disorders: a comparison of unipolar and bipolar patients. Journal of Affective Disorders 13, 83-92. 